See discussions, stats, and author profiles for this publication at: https://www.researchgate.net/publication/335566688

\title{
Ubiquitous music: Perspectives and challenges
}

Article in Journal of New Music Research · September 2019

DOI: 10.1080/09298215.2019.1659828

\section{CITATIONS}

2

3 authors:

Damián Keller

Universidade Federal do Acre

75 PUBLICATIONS 549 CITATIONS

SEE PROFILE

Victor Lazzarini

National University of Ireland, Maynooth

84 PUBLICATIONS 351 CITATIONS

SEE PROFILE

Some of the authors of this publication are also working on these related projects:

Creativity in degraded environments View project

Project Medusa View project
Flávio Luiz Schiavoni

Federal University of São João del-Rei

96 PUBLICATIONS 88 CITATIONS

SEE PROFILE 


\title{
Ubiquitous Music: Perspectives and Challenges
}

\author{
Damián Keller $^{\mathrm{a}}$, Flávio Schiavoni ${ }^{\mathrm{b}}$ and Victor Lazzarini ${ }^{\mathrm{c}}$ \\ ${ }^{a}$ NAP, Federal University of Acre, Brazil; b Federal University of São João del Rei, Brazil; ${ }^{b}$ \\ Maynooth University, Ireland
}

\author{
ARTICLE HISTORY \\ Compiled August 7, 2019
}

\begin{abstract}
This special volume features a selection of proposals that prompted positive and extensive discussions within the context of the Ubiquitous Music Workshop held at the Federal University of São João del Rei, MG, Brazil. In its eighth edition and featuring contributions from a host of international participants, this event provided a demonstration of the various approaches that characterise the research and practice of the ubimus field. In addition to the papers selected for this issue and the oral presentations, the workshop also included round-table discussions and artistic realisations, which are an important part of the work of many ubimus practitioners. These musical and artistic results are also addressed in the articles included in this special issue.
\end{abstract}

\section{Ubimus in 2019: an evolving field}

Ubiquitous music (ubimus) is an emergent field of research that combines several areas from sound and music computing, human computer interfaces, creativity studies, music education, with a strong social and community underpinning. The term owes its origins to concepts and ideas around ubiquitous computing (Weiser, 1991), connecting in particular with the principle that deep technologies "weave themselves into the fabric of everyday life until they are indistinguishable from it." (Weiser, 1991, 1). Informally, it is assumed that music is ubiquitous in modern society, more often than not experienced in a passive way. Our proposal is that ubiquitous music is a field of study which takes that assumption and considers it as an opportunity for creative participation that is open to all.

Since its beginnings in 2007, ubimus has featured a variety of artistic, social, and technological perspectives that highlight the field's potential for applications in diverse contexts. While the impact of the recent technological support for music making remains central in ubimus debates, the social and cognitive dimensions of ubimus research have gained strength due to the deployment of ubimus technology for educational and artistic endeavours. For instance, a topic such as creativity - increasingly tied to cultural and social factors (Glaveanu, 2013) - has been adopted as a relevant theme of ubimus research (Keller \& Lazzarini, 2015)) ${ }^{1}$. Strategies for fast knowledge transfer in collaborative music making emerge as alternatives to a long-standing vision on interaction that has been limited to the instrumental musical tradition (Machover

CONTACT D. Keller. Author. Email: dkeller@ccrma.stanford.edu; F. Schiavoni. Author. Email: fls@ufsj.edu.br; Victor Lazzarini. Author. Email: Victor.Lazzarini@mu.ie

${ }^{1}$ See also (Schiavoni et al., this issue). 
\& Chung, 1989). Despite the strong engagement of non-musicians in ubimus practices, some approaches that target fully trained, professionally oriented stakeholders still hold a place in recent ubimus initiatives ${ }^{2}$. Thus, current ubimus perspectives encompass a wide diversity of actors that range from casual participants to highly trained musicians.

A volume published in 2018 features reports on ubimus research that highlight the challenges and possibilities of this expanding field (Keller \& Barreiro, 2018). In their editorial, Keller and Barreiro point to two forces of attraction present in recent ubimus proposals. One force deals with the support of everyday creative practices. The authors highlight the difficulties encountered by projects that target mixed participants profiles, an issue addressed in the ubimus literature within the context of lay-musician interaction. While the professionally trained participants usually covet artistically relevant results, to engage in group musical activities may provide a sufficient reward for the untrained subjects. These contrasting sets of expectations could push the design initiatives toward solutions tailored for specific user profiles. Nevertheless, it remains to be seen whether it is possible to fulfil potentially contradicting sets of demands of multiple stakeholders participating in shared activities.

A partial answer to this issue is provided by the deployment of fast knowledgetransfer strategies. Keller and Barreiro $(2018,7)$ argue for an increased investment in tacit and implicit knowledge exchanges, exemplified by metaphors for creative action that take advantage of face-to-face cues. This perspective is illustrated by Handy, a metaphor that employs hands and torso movements for parametric control (Keller, Aliel, \& Silva, 2018). Furthermore, the exchange of implicit knowledge could also be enabled by verbal exchanges that do not involve domain-specific expertise. This expanded notion of musical knowledge transfer could also open a path to the inclusion of semantic cues in ubimus ecosystems, as exemplified by the deployment of the tool Playsound.space ${ }^{3}$.

An issue emerging within this avenue of research is how to employ abstract tokens without limiting the effectiveness of the interaction strategies. It remains to be seen whether Truax's (1980) design principle of generality vs. strength holds true for semantic exchanges in aesthetic decision making (Hazel, 2007). Truax suggests that effective musical interaction is achieved when the design attains a balance between the amount of information required from the user and the level of automation provided by the system. According to Truax, general systems tend to be very flexible but demand a lot of user work. Contrastingly, strong systems constrain the range of musical outcomes but gain efficiency in achieving specific goals. For instance, within the context of semantic strategies the general systems would involve highly specialized parametric descriptions to achieve specific sonic outcomes. The strong systems may be exemplified by the use of colloquial language - devoid of domain-specific terms and indicating characteristics that are applicable to a fairly large variety of sonic results. Though, an aspect not considered by Truax's model is that within the context of collaborative music making, the aesthetic decisions do not depend solely on the performance of the system. What is desired by one user may be rejected by other partners. There is a meta-dialogue that takes place during aesthetic decision-making that could be enhanced by sharing - beyond the results of the musical activity - the aesthetic motivations that lead to each particular decision ${ }^{4}$.

The second ubimus force identified by Keller and Barreiro 2018 targets the explo-

\footnotetext{
${ }^{2}$ Costalonga et al., this issue; Turchet et al., this issue.

${ }^{3}$ Stolfi et al., this issue

${ }^{4}$ See (Keller et al., this issue; Stolfi et al., this issue) for related proposals on this topic
} 
ration of novel forms of music making, continuing a research agenda heavily tilted toward the professional realm. This trend has origins in the discussions held during the initial ubimus workshops, highlighting three aspects: (1) The dissolution of the division of labour between composers, performers and audience in artistic practice; (2) The potential impact of ubimus initiatives on human development and well-being; (3) The influence of ubiquitous computing techniques on ubimus developments. The first topic fits within the context of the artistic initiatives powered by ubimus. Hence we save this discussion for the next section.

Regarding the second topic, in a recently published chapter Keller and Lima (2018) point out that the development of ubimus technologies for well-being and health is still in its infancy. A proposal by Timoney et al. (2014) targets the encouragement of regular physical exercise. This initiative is aligned with the popularisation of sports and fitness gadgets - including activity-tracking bracelets and smart watches - but it features an interesting enhancement: the ability to tune the musical contents considering the local context and the subject's needs. Thus, it paves the way to the application of musification techniques within the context of ubimus research Barrass (2015). Ubimus techniques hold a huge potential for deployment to enhance everyday activities, including health and fitness. We expect more rapid developments through the implementation of special-purpose programming tools and through low-cost hardware prototyping environments.

Based on the key role of lay participation in ubimus activities, on the social implications of music making outside of the artistic venues and on the substitution of creative products by creative potentials as relevant targets for ubimus research, Keller and Lima (2018) suggest that the technical aspects of ubiquitous computing may not be at the centre of the ubimus initiatives, after all. But there may be an area in which this argument does not hold. The development of ubimus technology for professional music making is well represented in the projects that led to the definition of the Internet of Musical Things (IoMusT). Two aspects are addressed by these proposals. On the one hand, ubimus deployments targeting professional audio services have provided a test field for the asynchronous support of remote audio processing (Zawacki \& Johann, 2012). On the other hand, ubimus artistic proposals - such as the Memory Tree Project (Ribeiro Netto et al., 2015) - have increased the participation of the audience as a key component of the artistic experience. The technologies and concepts underlying these initiatives are discussed by Turchet et al. (2018) and Keller and Lazzarini (2017). The intense synergy of the ubimus community has led to a unified view for the future deployments of the IoMusT (Turchet et al., 2018). Nevertheless, the IoMusT potential for novel forms of music making remains unexplored. When lay participants are included in artistic activities, support for interaction with remote resources is still a challenging issue (the strategies developed for InMesh ${ }^{5}$ and for Playsound.space ${ }^{6}$ provide illustrative examples of the difficulties). Furthermore, the settings where the musical activities take place may seriously limit the creative factors at play. For instance, the demands and expectations of subjects participating in musical activities in transitional spaces - such as public outdoor spaces or indoor spaces with intense circulation - are very different from the expectations of those involved in private or familiar settings, as typically featured in domestic activities (see the discussion on everyday musical creativity below). Consequently, the local social context may have a strong impact on the ability of the stakeholders to take full advantage of the IoMusT

${ }^{5}$ Keller et al., this issue.

${ }^{6}$ Stolfi et al., this issue. 
resources, even when some of these resources are accessed remotely. We look forward to more developments on this front.

\section{Artistic Practices in Ubimus}

Three papers in this special issue are directly relevant to the debate of ubimus in artistic practices. The first of these, Knowledge transfer in ecologically grounded approaches to ubimus: InMesh 1.0 deals with aspects relating to both everyday music-making and ecologically grounded music practices, under the guiding principles of interaction design (Bown, 2014). The article concentrates on the work that ultimately gave light to the piece Enmarañados / Emaranhados / InMesh 1.0 (Capasso, Keller, \& Tinajero, 2014), exploring how the decision-making process between the authors developed in the process of its realisation. This contribution also highlights an important aspect of ubimus research: the elucidation of the relationships between the creative strategies proposed by the artists and their creative outcomes. It summarises several important concepts derived from ecologically grounded musical practices, and discusses the ways in which knowledge transfer may be handled in collaborative settings. The paper also provides an experimental approach to the exploration of the proposed methodologies, which is quite novel in the way it treats an eminently artistic subject. From these, a number of findings are derived, which provide further ideas and resources for ubimus creative practices.

In line with the ecologically grounded artistic projects conducted during the 1990s, current eco-based practices encompass a panoply of approaches including instrumentally oriented techniques - such as those proposed by Burtner (2005), Connors (2015) and Keller et al. (this issue) - to proposals employing purely synthesized sonic sources (Di Scipio, 2008). This issue's articles Knowledge transfer (...) and Playsound.space: music improvisation in the browser using semantic queries report the use of creative surrogates as resources for collaborative aesthetic decision-making. As we will exemplify below, these initiatives may contribute to the research targeting everyday creative phenomena.

A recent review of ecologically based projects by Keller and Lazzarini (2017) asserts that ubimus ecologies may provide a promising venue for the expansion of creative practices. The authors propose the label behavioural ecologies for the ubimus systems that make heavy usage of social interactions and name the systems scaffolded on environmental features as multimodal ecologies. A third class of ecologies is comprised by the algorithmic meshworks that involve the use of decoupled resources yielding formal relational properties ${ }^{7}$. Nance's (2018) methods fit well within the proposed class of behavioural ecologies. Aural scores may be employed as creative surrogates to share sonic information that serves to constrain the decision-making processes. The constraints established by the aural scores function as molds for diverse musical solutions while keeping the consistency of the creative strategy. Diversity plus consistency seem to be two characteristics shared by many ecologically grounded methods.

Anthropological and philosophical discussions on ecologically oriented artistic practice seldom acknowledge their debt to the actual creative activity that predates them.

\footnotetext{
${ }^{7}$ A detailed discussion of material, social and formal relational properties is beyond the scope of this editorial. In a nutshell, relational properties are derived from the concept of affordance coined by psychologist J. J. Gibson in 1977 (Gibson, 1977). The proposal is still in development and we envisage further exchanges that could impact its meaning and its potential applications. Please see Keller et al. (2010) and Keller et al. (2014) for the concept's motivations and context.
} 
This gap has recently been pointed out by Connors (2017). "Keller's most recent research at the Amazon Center for Music Research, in conjunction with the Ubiquitous Music Group (Keller \& Lazzarini, 2017), has summarised the current trend in ecologically grounded methodologies and has proposed that ecological approaches to creative practice may provide an alternative to the mainstream anthropocentric and disembodied acoustic-instrumental paradigms." (Connors, 2017, 66). Within the context of her review of eco-grounded artistic works, Connors highlights the concept of 'ecologically based event' (Keller, 2000). When embedded in the context of everyday phenomena, creative music making provides multimodal events as units of action-perception (Keller, 2000). According to Connors if we invert the order and bring these words forward in time, we arrive at Manning and Massumi's (2014) 'event based ecology'.

Artistic applications of ubimus have also established fruitful exchanges with recent approaches to improvisational practices (Brown, Stewart, Hansen, \& Stewart, 2014). In Playsound.space (...), the authors describe the process of development and evaluation of the tool Playsound.space. This browser-based environment - implemented using the Web Audio $A P I^{8}$ - lets the users interact with samples available on the Internet. To avoid copyright infringement, the system only employs creative-commons audio content. The authors suggest that Playsound.space can be approached as a musical instrument that produces a rich palette of sounds without requiring musical expertise or virtuosity. To play with Playsound.space, participants use semantic tokens to search for samples in the Freesound ${ }^{9}$ database. The tool also provides translations of tokens to several languages. From the query, the system returns a collection of samples which are displayed as spectrograms. This visual representation helps users to decide which sounds to choose. The authors report initial experiments with musicians and laypeople doing free music improvisation and electroacoustic composition, indicating good usability and creativity support.

The final contribution to the debate on artistic practices leans heavily on exploiting technologies for ubimus. The Handy Metaphor: Touchless, bimanual interaction for the Internet of Musical Things explores the concept of IoMusT proposing a new metaphor for creative action. The Handy Metaphor, on which the work is based, is a bimanual, touchless interaction technique for application in conversational contexts, where access to musical hardware may not be supported. Its design is done through the development of two prototypes, Handy $H$, implemented on a small portable device, and Handy $S$, for standard desktop computers. The paper discusses their usage in an experimental setting, where their attributes are put through ubimus-oriented testing methodologies. The results raise a number of implications for interaction design within the scope of IoMusT-based deployments.

\section{Technological Contributions}

The present issue also dedicates significant space to technologically oriented contributions to ubimus research, exemplified in three papers: Understanding Biomechanical Constraints for Modelling Expressive UbiMus Performance: A Guitar Case Study, A ubiquitous smart guitar system for collaborative musical practice, and Addressing Creativity in Network Communication for Computer Music Interaction. As discussed in the previous section, professionally oriented initiatives coexist with socially more inclusive designs within the context of ubimus research. The first two papers provide good

${ }^{8}$ https://www.w3.org/TR/webaudio/

${ }^{9}$ http://www.freesound.org/ 
examples of proposals targeting highly trained users and involving the development of acoustic-instrumental techniques. The third proposal provides a broad discussion of emerging issues related to the technological developments of ubimus.

A guitar system using an acoustic guitar with an add-on and a smartphone application for collaborative music making is discussed in A ubiquitous smart guitar system (...). This instrument, classified as a Smart Musical Instrument (SMI) by the authors, is related to two research fields: NIME ${ }^{10}$ and ubimus. SMIs are described as a collocated or cloud-based, self-contained hub, supporting network connectivity to integrate musicians and devices in a collaborative way. The authors made an evaluation of usability, creativity support and overall experience in the context of ubiquitous musical activities with 18 participants, 6 females, 12 males, with ages 23 to 49 . All participants had musical training, 8 subjects were guitarists and the others had experience as electroacoustic-music performers. Participants were grouped in pairs, one guitarist and one electroacoustic musician that had not previous performances together. In this scenario, the instruments were considered easy to use and expressive.

Understanding Biomechanical Constraints (...) discusses the three classical roles in concert music, the composer, the performer and the audience, focusing on how to attain expressive performances based on musical scores. Two performance models are proposed, psychoacoustics-based and performer-based, followed by a discussion on what qualifies as an error in a musical performance and the role of such errors in musical expression. As part of this study, the authors report a set of experiments, employing various techniques to measure force, posture, speed and precision during guitar performances. The study of how biomechanical constraints interfere with performance practices can help us to create more ergonomic support strategies based on the human anatomy, as a way to deal with its limitations.

A final contribution to this special issue within the scope of technological approaches is Addressing Creativity in Network Communication (...). In this paper, the networked musical performances are explored through the lens of interaction and collaboration. The use of computer networks to foster collaboration dates from before the advent of the Internet (Bischoff, Gold, \& Horton, 1978). Its potential was greatly enhanced with the ubiquitousness of the world-wide web. Following a survey of artistic practices and technological approaches, the paper furnishes three examples where networks have been used as a key component to promote collaboration and interactivity. These experiences demonstrate how computers may be extended beyond their locality to enable sharing and collaboration in musical performances. Within the scope of ubimus perspectives, this technological context may not be limited to professional music-making, it may also provide a platform for artistic creation by non-musicians.

The authors highlight the key role of audience participation in current artistic practices including performances, installations and network-based music making. While they acknowledge the relevance of the technological support as a means to boost the creative possibilities, their discussion also encompasses a broad set of issues that have pushed the ubimus agenda beyond the realm of making new instruments or designing for self-expression. Telematic concerts, network music performance and laptop and mobile orchestras are offered as examples of music making centred around the acousticinstrumental model (see Bown et al. (2009); Keller, Flores, Pimenta, Capasso, and

${ }^{10} \mathrm{New}$ Interfaces for Musical Expression (NIME) is a community and also an annual conference that focuses on the development of digital musical instruments. Its original denomination was New Instruments for Musical Expression. Various researchers have criticised the implications of targeting instruments and self-expression as the main (and sometimes the only) objectives of musical interaction research (see Bown, Eldridge, and McCormack (2009); Gurevich and Treviño (2007) for two early examples of these critical analyses) 
Tinajero (2011); Parmar (2012) for previous critical discussions on this topic). The authors state that accessible and sustainable platforms for artistic usage are just one step to attain support for collaborations between non-musicians and musicians. From their perspective, the goals of design should include the expansion of creativity, the encouragement of sustainable artistic practices and more intense cultural sharing.

An open question in this proposal is how to enable exchanges based on semantic content when the cultural referents are different. An area where this issue seems to be particularly problematic is timbre interaction (Keller, 2017; Stolfi, Milo, \& Barthet, 2018). During the Eighth UbiMus Workshop, the issue of how to handle timbre characteristics was partially addressed in various projects. According to Keller (2017), timbre manipulation triggers an interplay of acoustic and categorical information. As an attribute of sound, it can be applied to sonic interaction for aesthetic goals. Furthermore, conceptualising timbre is still problematic because of the wide field of possibilities and the multiple dimensions involved, that could include kingdoms (acoustic vs. electronic sounds), families (liquid vs. solid sounds), genera (synthesis algorithms) and species (instrumental techniques). Given this state of affairs, timbre interaction could require: 1. Support strategies with sufficient generality to encompass multiple levels of timbristic manipulation, and 2. Audio synthesis and processing techniques that enable access to perceptually meaningful timbre parameters. Stolfi et al (2018) propose the use of semantics-based tools to deal with sonic content. Within the context of the Eighth UbiMus Workshop, this strategy was exemplified by a collaborative performance that involved retrieving sounds from a database through the use of keywords in English. Given that the system supports the use of translations, it would be interesting to establish comparisons between usage by native-English speakers and usage of translated tokens. Possible limitations include not only the accuracy of the automatic translation techniques, they also encompass the level of familiarity with the sonic resources which seems to be closely related to the previous listening experiences of the stakeholders. Thus, cultural context emerges as a factor that may shape future technological developments in ubimus.

\section{Conclusions}

This issue of the Journal of New Music Research - dedicated to ubiquitous music theory and practice - builds on a growing body of work and furthers the ubimus research agenda by introducing new ideas, concepts and projects, such as the IoMusT, the notions of knowledge transfer in artistic settings, the use of semantics in ubimus contexts and the impact of recent technological developments on ubimus practices.

The three papers featured in the section on artistic contributions point to emerging issues to be addressed by future ubimus projects. The use of technology as a knowledgesharing mechanism has implications on multiple contexts beyond music making. From the massive distribution of fake news to the negative impact of the adoption of personal devices for social interaction, the consequences of the lack of face-to-face exchanges raise red flags on the function of technology as a tool for community-oriented creative goals. Group music making is consistently documented as boosting social cohesiveness. But how does the insertion of technological support impact the social side of musical interaction? Access to the massive material resources potentially furnished by IoMusT deployments may drastically modify the sonic landscape of transitional spaces, for instance, through the adoption of market-driven usage of multimedia displays in subway, train and bus terminals. As mentioned in the pioneering discussions fostered by 
Schafer (1977) and by Attali (2001), public spaces are quickly becoming dumps of sonic garbage. A similar trend is observed by Truax (2012) regarding the quality of the sonic material available on virtual spaces. How should we deal with sonic garbage, or better, how should we approach the problem of designing a musically sustainable future? Given the intense exchanges among artists, educators and technologists on these topics, we believe that ubimus may provide a field for interdisciplinary convergence that could eventually furnish alternatives to the recipes based on nineteenth-century musical practices.

The three contributions to the technological advancement of ubimus featured on this issue provide a balance of the development of well-established traditions enhanced by the incorporation of recent technology. While on the one hand, acoustic-instrumental proposals have dominated computer-based compositional practices since the very beginning of the computer music field (Hiller \& Isaacson, 1959), on the other hand the facilitated access to technological resources in settings and contexts not originally meant for artistic goals has pushed the limits of what musicians understand as musicmaking in the 21st century. As demonstrated in the applications featured in these three articles, ubimus research can provide expanded opportunities for those trained in the classical instrumental tradition without excluding the participation of a larger range of creative partners. Cognitively grounded synthesis and control techniques, such as those proposed in Understanding (...) and in A ubiquitous smart guitar (..), could be featured in automated systems that do not necessarily demand long training in guitar performance techniques. This perspective is supported by concepts such as the ubimus ecosystems (Lazzarini, Keller, Pimenta, \& Timoney, 2014) that entail the modular incorporation of resources depending on the specific settings, activity demands and participants profiles. As exemplified by the usage proposed by Zawacki and Johann (2012, IoMusT-based infrastructure could include highly specialised hardware such as vintage analogue synthesisers - to be handled through interaction metaphors that do not demand long training or domain-specific knowledge. We are still far from reaching this stage, but the contributions featured in this section indicate that several ubimus proposals may eventually converge in scenarios that balance specialised knowledge with casual participation (see discussion on lay-musician interaction).

Besides showcasing a wide-ranging sample of ubimus projects, this special issue highlights a number of topics for future research. It also brings to our attention the various challenges involved in the field, setting a milestone in its development. We hope that this initiative will also trigger new ideas in related areas that deal with the philosophical and social implications of creativity, sustainability and the responsible development of technology. These issues, along with an emphasis on the education of the new generations, ought to be central for any research that is ethically engaged with the many challenges faced by humanity in the 21 st century.

\section{References}

Attali, J. (2001). Bruits. Paris: Fayard, Presses Universitaires de France.

Barrass, S. (2015). The musification of furniture in the form of a pouf-doodle. In Proceedings of the workshop on ubiquitous music (vi ubimus). Vaxjo, Sweden: Ubiquitous Music Group.

Bischoff, J., Gold, R., \& Horton, J. (1978). Music for an interactive network of microcomputers. Computer Music Journal, 2(3), 24-29.

Bown, O. (2014, June 10-13). Empirically grounding the evaluation of creative systems: 
Incorporating interaction design. In Proceedings of the fifth international conference on computational creativity (iccc 2014) (p. 112-119). Libjubljana, Slovenia: ICCC.

Bown, O., Eldridge, A., \& McCormack, J. (2009, 7). Understanding interaction in contemporary digital music: From instruments to behavioural objects. Organised Sound, 14(2), 188-196.

Brown, A. R., Stewart, D., Hansen, A., \& Stewart, A. (2014). Making meaningful musical experiences accessible using the ipad. In D. Keller, V. Lazzarini, \& M. S. Pimenta (Eds.), Ubiquitous music (p. 65-81). Heidelberg and Berlin: Springer International Publishing.

Burtner, M. (2005, 4). Ecoacoustic and shamanic technologies for multimedia composition and performance. Organised Sound, 10(1), 3-19.

Capasso, A., Keller, D., \& Tinajero, P. (2014). Enmaraados / emaranhados / inmesh 1.0 [ubiquitous music work]. MediaNoche Gallery, New York, NY.

Connors, T. M. (2015). Audiovisual installation as ecological performativity. In Proceedings of the 21st international symposium on electronic art (isea2015). Vancouver, Canada: ISEA.

Connors, T. M. (2017). Audiovisual installation as ecological performativity: A creative research practice (Doctor of Philosophy in Music). Hamilton, New Zealand: The University of Waikato.

Di Scipio, A. (2008). Émergence du son, son d'emergence: Essai d'épistémologie expérimentale par un compositeur. Intellectica, 48-49, 221-249.

Gibson, J. J. (1977). The theory of affordances. In R. Shaw \& J. Bransford (Eds.), (Vols. Perceiving, Acting, and Knowing: Toward an Ecological Psychology, p. 67-82). Mahwah, NJ: Lawrence Erlbaum Associates.

Glaveanu, V. P. (2013). Rewriting the language of creativity: The five a's framework. Review of General Psychology, 17(1), 69-81.

Gurevich, M., \& Treviño, J. R. (2007). Expression and its discontents: toward an ecology of musical creation. In Proceedings of the 7th international conference on new interfaces for musical expression (nime '07) (pp. 106-111). New York, NY: ACM.

Hazel, P. (2007). Generality vs. strength. Retrieved from http://www.paulhazel.com/2007/ 05/15/generality-vs-strength/

Hiller, L., \& Isaacson, L. M. (1959). Experimental music: Composition with an electronic computer. New York, NY: McGraw-Hill.

Keller, D. (2000, December). Compositional processes from an ecological perspective. Leonardo Music Journal, 10, 55-60.

Keller, D. (2017). Strategies for timbre interaction in ubimus contexts (stratégies pour l'interaction du timbre dans les contextes de musique ubiquitaire). In Actes des journées $d$ études internationales crillash-adecam $/ m c$. Martinique, France: Université des Antilles.

Keller, D., Aliel, L., \& Silva, C. R. (2018). The handy metaphor: Bimanual, touchless interaction for the internet of musical things. In Anais do workshop em música ubíqua / proceedings of the ubiquitous music workshop (ubimus 2018). São João del Rei, MG: Ubiquitous Music Group.

Keller, D., \& Barreiro, D. L. (2018). Ubiquitous music section: Forces of attraction and challenges in ubimus research (editorial). Revista Vórtex, 6(2), 1-14.

Keller, D., Barreiro, D. L., Queiroz, M., \& Pimenta, M. S. (2010). Anchoring in ubiquitous musical activities. In Proceedings of the international computer music conference (p. 319326). Ann Arbor, MI: MPublishing, University of Michigan Library: Ann Arbor, MI: MPublishing, University of Michigan Library.

Keller, D., Flores, L. V., Pimenta, M. S., Capasso, A., \& Tinajero, P. (2011). Convergent trends toward ubiquitous music. Journal of New Music Research, 40(3), 265-276.

Keller, D., \& Lazzarini, V. (2015). Special issue on creativity-centered design and the digital arts. Journal of Cases in Information Technology(17), i-v.

Keller, D., \& Lazzarini, V. (2017). Ecologically grounded creative practices in ubiquitous music. Organised Sound, 22(1), 61-72. 
Keller, D., Lazzarini, V., \& Pimenta, M. S. (2014). Ubimus through the lens of creativity theories. In D. Keller, V. Lazzarini, \& M. S. Pimenta (Eds.), Ubiquitous music (p. 323). Berlin and Heidelberg: Springer International Publishing.

Keller, D., \& Lima, M. H. (2018). Ecologically grounded creative practice in ubimus: Sons do cap (práticas cognitivo-ecológicas em ubimus: Sons do cap). In Ubiquitous music applications (aplicaões em música ubíqua). São Paulo, SP: ANPPOM.

Lazzarini, V., Keller, D., Pimenta, M., \& Timoney, J. (2014). Ubiquitous music ecosystems: Faust programs in csound. In D. Keller, V. Lazzarini, \& M. S. Pimenta (Eds.), Ubiquitous music (p. 129-150). Berlin and Heidelberg: Springer International Publishing.

Machover, T., \& Chung, J. (1989). Hyperinstruments: Musically intelligent and interactive performance and creativity systems. In Proceedings of the international computer music conference (icmc 1989) (p. 186-190). Ann Arbor, MI: MPublishing, University of Michigan Library.

Manning, E., \& Massumi, B. (2014). Thought in the act: Passages in the ecology of experience. Minneapolis, MN: University of Minnesota Press.

Nance, R. (2018). Music as a plastic art: An ecological strategy facilitating emergence in an instrumental composition ecology. In Anais do workshop em música ubíqua / proceedings of the ubiquitous music workshop (ubimus 2018). São João del Rei, MG: Ubiquitous Music Group.

Parmar, R. (2012). The garden of adumbrations: Reimagining environmental composition. Organised Sound, 17(3), 202-210.

Ribeiro Netto, A., Castheloge, L., Oliosi, A., Mateus, A., Costalonga, L., \& Coura, D. (2015). Memory tree: Multimedia interactive installation (árvore das memórias). In Proceedings of the xv brazilian symposium on computer music (sbcm 2015) (p. 76-82). Campinas, SP: SBC.

Schafer, R. M. (1977). The tuning of the world. New York, NY: Knopf.

Stolfi, A., Milo, A., \& Barthet, M. (2018). Cannibal soundscape [ubiquitous music work]. In Anais do workshop em música ubíqua / proceedings of the ubiquitous music workshop (ubimus 2018). São João del Rei, MG: Ubiquitous Music Group.

Timoney, J., Lazzarini, V., Ward, T., Villing, R., Conway, E., \& Czesak, D. (2014). The beathealth project: Synchronizing movement and music. In D. Keller, M. H. Lima, \& F. Schiavoni (Eds.), Proceedings of the $v$ workshop on ubiquitous music (v ubimus). Vitória, ES: Ubiquitous Music Group.

Truax, B. (1980). The inverse relation between generality and strength in computer music programs. Interface, $9(1), 49-57$.

Truax, B. (2012). Music, soundscape and acoustic sustainability. Moebius Journal, 1.

Turchet, L., Fischione, C., Essl, G., Keller, D., \& Barthet, M. (2018). Internet of musical things: Vision and challenges. IEEE Access, 6, 61994-62017.

Weiser, M. (1991). The computer for the 21st century. Scientific american, 265(3), 94-105.

Zawacki, L., \& Johann, M. (2012). A prospective analysis of analog audio recording with web servers. In Anais do workshop em música ubiqua / proceedings of the ubiquitous music workshop (ubimus 2012). São Paulo, SP: Ubiquitous Music Group. 